\title{
A Simple Quantitative Procedure for Inoculation of Safflower with Teliospores of the Rust Fungus, Puccinia carthami
}

\author{
William L. Bruckart, USDA-ARS-FDWSRU, 1301 Ditto Avenue, Fort Detrick, MD 21702-5023
}

\begin{abstract}
Bruckart, W. L. 1999. A simple quantitative procedure for inoculation of safflower with teliospores of the rust fungus, Puccinia carthami. Plant Dis. 83:181-185.

A procedure is needed to determine susceptibility of safflower seedlings to teliospore inoculations of foreign accessions of Puccinia jaceae, a candidate agent for biological control of Centaurea solstitialis (yellow starthistle). The indigenous safflower rust pathogen, $P$. carthami, served as both model and basis for a future comparative study of these two rust fungi on safflower. The procedure involves inoculation of 2-day-old safflower seedlings on the hypocotyl near the base of the cotyledons with a known number of teliospores suspended in a 1- $\mu$ l drop of a $0.1 \%$ water agar and wetting agent carrier. Advantages of this procedure include (i) quantification, by spore type, of inoculum applied to each seedling, (ii) precise placement of inoculum on test plants, and (iii) conservation of inoculum. Results were verified in studies with two safflower cultivars inoculated with $0,15,60$, or 240 teliospores of either of two isolates of $P$. carthami. Plant height and dry weight data collected 6 weeks after inoculation revealed significant interactions for cultivar $\times$ inoculum concentration and for isolate $\times$ inoculum concentration. Similar results were achieved when safflower seeds were rolled in dry teliospores of $P$. carthami but not when seedlings grew through teliospore-infested sand. The latter two approaches (dry teliospore and infested sand inoculation) require much more inoculum and are only semiquantitative. The microliter drop procedure has potential usefulness in host range and quantitative studies involving other pathogens, including bacteria, fungi, and nematodes.
\end{abstract}

Additional keywords: risk assessment

Yellow starthistle (Centaurea solstitialis L., YST) is a serious weed pest targeted for biological control, and Puccinia jaceae G. Otth is currently being evaluated for this purpose (1). Central to the risk assessment of $P$. jaceae is an host range determination that includes safflower (Carthamus tinctorius L.), a close relative of YST. Urediniospores of $P$. jaceae from YST or diffuse knapweed (Centaurea diffusa Lam.) infected safflower leaves in host range determinations $(1,11)$, but disease was very limited and $P$. jaceae could not be maintained on currently grown safflower cultivars under optimal greenhouse conditions.

Safflower can be infected by an indigenous rust fungus, Puccinia carthami Corda, in the U.S. Side-by-side comparisons between $P$. carthami and $P$. jaceae

Corresponding author: W. L. Bruckart E-mail: bruckart@asrr.arsusda.gov

Mention of a trademark or a proprietary product does not constitute a guarantee or warranty by the U.S. Department of Agriculture and does not imply its approval to the exclusion of other products that may also be suitable.

Accepted for publication 5 November 1998.

Publication no. D-1998-1214-02R

This article is in the public domain and not copyrightable. It may be freely reprinted with customary crediting of the source. The American Phytopathological Society, 1999. were used in the evaluation of the YST rust to clarify issues of risk concerning susceptibility of safflower to foliar infections of $P$. jaceae $(3,4)$. These studies showed clearly that disease from urediniospores of the YST strain was much less than disease from similar concentrations of $P$. carthami urediniospores on safflower (1). For these reasons, $P$. jaceae is not considered to be potentially damaging to safflower as a foliar pathogen (1) in the event it is introduced into the U.S. for biological control of YST.

To complete the evaluation of $P$. jaceae for biological weed control, it is necessary to determine if teliospores of $P$. jaceae can initiate infection and damage of safflower seedlings. This concern is based on the potential of $P$. carthami to infect safflower seedlings, i.e., the seedling phase of the safflower rust disease $(6,18)$ that occurs from infestations of seeds and soil with teliospores of $P$. carthami (13). Published methods for the inoculation of safflower with teliospores of $P$. carthami (12,16-19) are simple and reproducible, but they are not sufficiently precise and quantitative for the intended comparisons with $P$. jaceae. Several other methods have been described for the quantitative inoculation of plants $(5$, $15)$, but none were satisfactory for the intended research with $P$. jaceae teliospores.

The objective of this research was to develop a procedure for the quantitative inoculation of safflower seedlings with telio- spores, using $P$. carthami as a model. Results of this research will relate directly to comparative studies between two Puccinia spp. $(3,4)$ as part of a risk assessment of $P$. jaceae for biological control of YST.

\section{MATERIALS AND METHODS}

Fungal isolates, plant cultivars, and growing conditions. All experiments were conducted in 10 -cm-diameter clay pots with a pasteurized greenhouse soil mix containing 80 parts Premier ProMix BX, 40 parts each of field soil, peat moss, and vermiculite, 30 parts perlite, 20 parts sand, plus lime, 10-10-10 liquid fertilizer, and AquaGro 2000-G, a wetting agent.

Two field isolates of $P$. carthami, CAL from Davis, CA, and MEX from Ciudad Obregon, Mexico, were included in these studies. The proportions of teliospores, based on microscopic observations and counts, were $82.3 \pm 4.5 \%$ and $90.2 \pm 5.3 \%$ for the CAL and MEX isolates, respectively. Germination of teliospores of each isolate was at least $75 \%$. Urediniospores in these lots did not germinate due to the prolonged period of storage under refrigeration.

The safflower cultivar Pacific-1 (Pac-1; from J. Klisiewicz) was used in every experiment because it was very susceptible to $P$. carthami in earlier studies with urediniospores (1). In most of the experiments, a second cultivar, either Cal/West-74 (C/W74; from CalWest Seeds, Woodland, CA) or UC-41 (from J. Klisiewicz), was included for comparison, because these were less susceptible to $P$. carthami in the earlier studies with urediniospores (1).

Safflower seeds were surface sterilized in $1 \% \mathrm{NaOCl}$ plus 3 drops of polyoxyethylene sorbitan monolaurate (Tween 20)/100 $\mathrm{ml}$ for $5 \mathrm{~min}$ prior to each experiment. Seeds or seedlings were planted by placing them on the surface of the soil mix described and covering them with $2.5 \mathrm{~cm}$ of sand. All pots were placed in a climatecontrolled greenhouse for 3 weeks at 12 to $14^{\circ} \mathrm{C}$ night and 15 to $20^{\circ} \mathrm{C}$ daytime temperatures. Pots were watered by mist twice per week with $2.5 \mathrm{~cm}$ of water. Plants were moved to a 21 to $25^{\circ} \mathrm{C}$ greenhouse for an additional 2 weeks and watered only when visible wilting of control plants occurred, unless otherwise noted. All experiments were conducted in a greenhouse facility designed for the containment of foreign plant pathogens (10).

Plant inoculations. Three methods of inoculation were evaluated: (i) dry spore, 
(ii) infested sand, and (iii) wet spore. Dry spore inoculations were made by rolling dry safflower seeds in a known weight of spores and planting as described. The final weight of spores applied was determined in each experiment by weighing the inoculum remaining after treatment. Data on spore weights from 11 inoculations (minimum of 20 seeds each) were used to calculate the average amount of inoculum applied by this procedure.

For the infested sand method, seedlings were planted so that they grew through sand artificially infested with teliospores. One untreated seed of either Pac-1 or C/W74 safflower was placed on soil in pots as described above, and a 2.5-cm-diameter plastic column was placed over each seed. The column was filled $2.5 \mathrm{~cm}$ high with sand artificially infested with either 0.1 or $1.0 \mathrm{mg}$ of dry spores of $P$. carthami. The remainder of the soil surface in each pot was covered with $2.5 \mathrm{~cm}$ of noninfested sand while the plastic column was in place. The column was removed, leaving 12.25 $\mathrm{cm}^{3}$ of infested sand directly over the seed. Twenty pots were set up for each combination of cultivar and treatment. Experimental design and data analysis are described below. The experiment was conducted with each isolate of $P$. carthami.

Wet spore inoculations were initiated to improve quantification and control of the inoculation process. Inoculum was suspended in a $0.1 \%$ water agar plus wetting

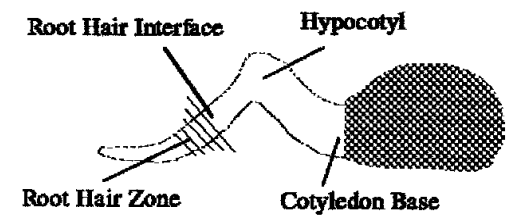

Fig. 1. Locations for inoculation of the primary root of a 2-day-old safflower seedling for data presented in Table 2. Protocol proposed involves inoculations on the hypocotyl at the base of the cotyledons ("Cotyledon Base"). agent (WAWA) carrier. Wetting agents used in these experiments were either a silicone-polyether copolymer (Silwet L-77; Loveland Industries, Greeley, $\mathrm{CO}$ ) or Tween 20 at 0.2 and $0.125 \%$ ( $\mathrm{vol} / \mathrm{vol})$, respectively. The addition of water agar to the carrier kept the teliospores in suspension, facilitating both quantification of teliospores and inoculation of seedlings (7). Two-day-old safflower seedlings were inoculated with a 1- $\mu$ l drop of spores in WAWA, planted, and grown as described earlier.

Inoculum was delivered as weight of spores per seed or seedling in the initial wet spore inoculations. For the remaining series of experiments, inoculations were quantified in terms of the number of teliospores per seed or seedling. Three to $5 \mathrm{mg}$ of spores was mixed in $100 \mu \mathrm{l}$ of WAWA. Concentration of teliospores was estimated in a $10^{-2}$ dilution of the stock suspension by counting the teliospores in five $1-\mu \mathrm{l}$ drops on a glass slide with a microscope at $\times 100$ magnification. The number of teliospores estimated per microliter of stock suspension was adjusted to the highest desired treatment concentration by diluting with WAWA, and dilutions were made from this to obtain the remaining spore concentrations. Verification of teliospore counts was done with $1-\mu \mathrm{l}$ drops as described. Minor adjustments were made, if necessary, in the volume of WAWA delivered to each seedling on the basis of verification counts. Teliospore germination was determined by placing a minimum of five $1-\mu \mathrm{l}$ drops of treatment suspension on $1.5 \%$ water agar plates containing a germinating safflower seed (8) and counting spore germination percentages determined after 1 week.

Experiments. Following preliminary tests with dry spore or infested sand methods, comparative experiments were conducted with each isolate of $P$. carthami. Twenty pots of Pac-1 and CW-74 were used with each treatment combination.

Table 1. Weighted least square means for dry weight and height from inoculation of two safflower cultivars $^{\mathrm{w}}$, Pacific-1 (Pac-1) or Cal/West-74 (C/W-1), with teliospores of Puccinia carthami ${ }^{\mathrm{w}}$

\begin{tabular}{|c|c|c|c|c|c|c|c|c|}
\hline \multirow[b]{3}{*}{ Inoculation method ${ }^{x}$} & \multicolumn{4}{|c|}{ Dry weight (g) } & \multicolumn{4}{|c|}{ Height $(\mathbf{c m})$} \\
\hline & \multicolumn{2}{|c|}{ CAL } & \multicolumn{2}{|c|}{ MEX } & \multicolumn{2}{|c|}{ CAL } & \multicolumn{2}{|c|}{ MEX } \\
\hline & Pac-1 & $\mathrm{C} / \mathrm{W}-74$ & Pac-1 & C/W-74 & Pac-1 & C/W-74 & Pac-1 & C/W-74 \\
\hline Control & $0.91 \mathrm{a}^{\mathrm{y}}$ & $0.73 \mathrm{a}$ & $0.55 \mathrm{a}$ & $0.54 \mathrm{a}$ & $57.9 \mathrm{ab}$ & $41.8 \mathrm{a}$ & $46.7 \mathrm{ab}$ & $22.3 \mathrm{a}$ \\
\hline Sand, $0.1 \mathrm{mg} /$ plant & $0.96 \mathrm{a}$ & $0.71 \mathrm{a}$ & $0.55 \mathrm{a}$ & $0.43 \mathrm{~b}$ & $57.8 \mathrm{ab}$ & $41.5 \mathrm{a}$ & $38.9 \mathrm{~b}$ & $16.2 \mathrm{~b}$ \\
\hline Sand, $1.0 \mathrm{mg} / \mathrm{plant}$ & $0.81 \mathrm{a}$ & $0.055 \mathrm{a}$ & $0.55 \mathrm{a}$ & $0.46 \mathrm{ab}$ & $60.8 \mathrm{a}$ & $43.2 \mathrm{a}$ & $42.4 \mathrm{ab}$ & $21.9 \mathrm{a}$ \\
\hline $\begin{array}{l}\text { Dry @ } 0.16 \mathrm{mg} / \text { plant } \\
\text { Reduction }(\%)^{\mathrm{z}}\end{array}$ & $\begin{array}{l}0.24 \mathrm{~b} \\
(73.6)\end{array}$ & $\begin{array}{l}0.61 \mathrm{a} \\
(16.4)\end{array}$ & $\begin{array}{l}0.15 \mathrm{~b} \\
(72.7)\end{array}$ & $\begin{array}{l}0.50 \mathrm{ab} \\
(7.4)\end{array}$ & $49.5 \mathrm{~b}$ & $32.5 \mathrm{~b}$ & $56.7 \mathrm{a}$ & $23.0 \mathrm{a}$ \\
\hline
\end{tabular}

${ }^{\mathrm{w}}$ Cultivars were either very susceptible (Pac-1) or moderately susceptible (C/W-74) to the foliar phase of safflower rust. Data represents results from two separate experiments, one with a field isolate from California (CAL) and the other with a Mexican (MEX) isolate

${ }^{x}$ Plants were inoculated either directly by dusting seeds with teliospores (Dry) or indirectly by planting inoculated seeds under a column of sand infested with teliospores (Sand).

${ }^{y}$ Means followed by the same letter in each column are not statistically significantly different $(\mathrm{P} p=$ 0.05 ), based on the $t$ test option in the general linear models procedure (SAS Institute, Cary, NC). Means are the average of 20 observations.

${ }^{\mathrm{z}}$ Calculated, for dry weight only, by: [Dry weight (Control) - Dry weight (Dry) / Dry weight $($ Control) $] \times 100$.

Two experiments, one for each isolate, were conducted to determine the importance of inoculum placement on seedlings and disease development on safflower plants. Pac-1 seedlings each were inoculated with $20 \mu \mathrm{g}$ of spores in a $1-\mu \mathrm{l}$ drop of WAWA at four locations along the hypocotyl and root (Fig. 1). Drops were allowed to dry before seedlings were planted. Ten seedlings were inoculated for each combination of isolate and treatment. Based on results from these experiments, seedlings in subsequent studies were inoculated on the hypocotyl at the base of the cotyledons (Fig. 1).

To measure the effects of isolate, inoculum concentration, cultivar, and watering regime on damage by $P$. carthami, 10 seedlings each of Pac-1 and UC-41 were inoculated with $1-\mu \mathrm{l}$ drops containing 0 , 15,60 , or 240 teliospores of each isolate. Seedlings were planted and grown at 12 to $14^{\circ} \mathrm{C}$ with misting twice per week during the first 3 weeks. Plants then were moved to a greenhouse maintained at 21 to $25^{\circ} \mathrm{C}$, separated into two groups, and either watered on a daily basis (no wilting) or watered after control plants began to wilt (reversible wilting).

Experimental design and data analysis. Each experiment was run as a randomized complete design with pots (one plant per pot) as replicates. Data were recorded on emergence, post-emergence damping-off, plant area diseased (percentage of hypocotyl), pustule development $(0$ to 4 rating in which $0=$ no pustule and $4=$ heavy sporulation), plant height $(\mathrm{cm})$, leaves (number), and plant fresh and dry weights $(\mathrm{g})$, for each study. Weighted least square means were calculated and data evaluated with the SAS (SAS Institute, Cary, NC) general linear models (GLM) procedure. Sources of variation included main effects and their interactions. Mean separation was based on comparing probability for differences (SAS, PDIFF procedure) between weighted least square treatment and interaction means. Treatment and interaction means were considered significantly different at $P \leq 0.05$. Interactions identified from the GLM procedure were clarified on the basis of the statistical separation of interaction means. Categorical data for disease ratings from the inoculum concentration experiment were subject to nonparametric analysis (SAS, NPAR1WAY procedure) for the main effect, watering regime.

\section{RESULTS}

Dry spore versus sand column inoculation of safflower. The amount of inoculum estimated to adhere to each seed rolled in dry spores was $0.219 \mathrm{mg}$ $(\mathrm{CI}[P=0.05]= \pm 0.176 \mathrm{mg}, n=11 \mathrm{ex}-$ periments) for both the MEX and CAL isolates. Dry weight of Pac-1, but not C/W-74, was significantly less than the 
controls by an average of $73.2 \%$ for both isolates of $P$. carthami (Table 1), and the cultivar $\times$ treatment interaction was significant $(P=0.001)$ for each isolate. Plant heights were significantly less for both cultivars inoculated with dry spores of the CAL, but not the MEX, isolate. The cultivar $x$ treatment interaction for either isolate was not significant for plant height data.

Plant dry weights and heights were not less than controls when seedlings grew through sand columns infested with teliospores of the CAL isolate of $P$. carthami. The mean dry weight of $\mathrm{C} / \mathrm{W}-74$ in the MEX isolate at $0.1 \mathrm{mg}$ treatment was significantly less than the controls, by $20.3 \%$, and plant heights for both Pac-1 and C/W74 were significantly less than controls in the same treatment, by 16.7 and $27 \%$, respectively.

Wet spore inoculation of seed; placement of inoculum. Greatest reductions in both plant dry weights $(73 \%)$ and heights $(52 \%)$ occurred when the drop of inoculum was placed on the hypocotyl at the base of the cotyledons (Table 2). The amount of damage was inversely proportional to distance from the cotyledons for inoculation, and there was no reduction in either dry weight or height when inoculum was placed in or near the root hairs (Table 2).

Wet spore inoculation of seed; inoculum concentration and watering regime. The main effect of watering regime was not significant $(P=0.264$ and 0.124 for dry weight and height, respectively) following inoculation of both safflower cultivars with each isolate at different concentrations of teliospores.

A significant interaction was noted for inoculum concentration $\times$ cultivar $(P=$ 0.020 and 0.015 for dry weight and height, respectively). Dry weight of Pac-1 inoculated with 240 teliospores per plant was reduced by $57 \%$ (Table 3 ) compared with a $27 \%$ reduction of UC41. Similar differences between the cultivars were noted for plant height data (Table 4).

The interaction of inoculum concentration $\times$ isolate also was significant for the two variables $(P=0.009$ and 0.037 for dry weight and height, respectively). Dry weight of safflower inoculated with the MEX isolate at 240 teliospores per plant was reduced by $57 \%$ (Table 3 ) compared with a $23 \%$ reduction with the CAL isolate. These differences also were reflected in the plant height data (Table 4).

Although watering regime did not cause significant effects on yield components (plant dry weight and height), disease rating and plant area diseased were greater when plants were allowed to wilt before watering. This was significant for disease ratings only at the lower doses of teliospores (15 and 62.5 per seedling) and when plants of either cultivar were inoculated with the CAL isolate (Table 5), based on the Kruskal-Wallis test (chi-square approximation). Plant area diseased also was significantly greater when plants were allowed to wilt before watering $(31.2 \%$ for both cultivars), compared with $21.0 \%$ when plants were not allowed to wilt $(P=$ 0.001 , paired $t$ test for data sorted by cultivar and treatment).

Table 2. Weighted least square means of dry weights and heights from the safflower cultivar, Pacific1, 6 weeks after inoculation with teliospores of field isolates of Puccinia carthami placed at different locations on 2-day-old seedlings ${ }^{\mathrm{w}}$

\begin{tabular}{lllllll}
\hline & \multicolumn{2}{c}{ Dry weight $(\mathbf{g})$} & & \multicolumn{2}{c}{ Height $(\mathbf{c m})$} \\
\cline { 2 - 3 } \cline { 5 - 6 } Location of inoculations $^{\mathbf{x}}$ & CAL & MEX & & CAL & MEX \\
\hline Control & $3.4 \mathrm{a}^{\mathrm{y}}$ & $2.2 \mathrm{a}$ & & $47.9 \mathrm{ab}$ & $42.2 \mathrm{a}$ \\
Within the root hairs & $3.4 \mathrm{a}$ & $1.5 \mathrm{a}$ & & $54.6 \mathrm{a}$ & $33.0 \mathrm{a}$ \\
Hypocotyl at the root hairs & $3.0 \mathrm{ab}$ & $1.9 \mathrm{a}$ & & $50.8 \mathrm{ab}$ & $40.1 \mathrm{a}$ \\
Hypocotyl & $1.9 \mathrm{~b}$ & $1.5 \mathrm{a}$ & & $34.8 \mathrm{~b}$ & $29.6 \mathrm{ab}$ \\
Base of cotyledons & $0.9 \mathrm{c}$ & $0.6 \mathrm{~b}$ & & $22.0 \mathrm{c}$ & $20.2 \mathrm{~b}$ \\
Reduction $(\%)^{\mathrm{z}}$ & $(73.5)$ & $(72.7)$ & & $(54.1)$ & $(52.1)$ \\
\hline
\end{tabular}

${ }^{\mathrm{w}}$ Data represents results from two separate experiments, one with an isolate from California (CAL) and the other with a Mexican (MEX) isolate

x Illustrated in Figure 1. "Hypocotyl at the root hairs" = "Root Hair Interface" in Figure 1.

${ }^{y}$ Means followed by the same letter in each column are not statistically significantly different $(P=$ 0.05 ), based on the $t$ test option in the general linear models procedure (SAS Institute, Cary, NC). Means are the average of 10 observations.

${ }^{z}$ Calculated, for dry weight only, by: [Dry weight (Control) - Dry weight (Dry) / Dry weight $($ Control) $] \times 100$

Table 3. Weighted least square means for dry weights of two safflower cultivars, Pacific-1 (Pac-1) and UC-41, after inoculation with a 1- $\mu$ l drop containing a known number of teliospores of Puccinia carthami isolates from California or Mexico placed on the hypocotyl near the base of the cotyledons of 2-day-old seedlings ${ }^{\mathrm{w}}$

\begin{tabular}{|c|c|c|c|c|c|c|c|c|c|}
\hline \multirow[b]{3}{*}{ Inoc Conc (T) } & \multicolumn{8}{|c|}{ Isolate (I) } & \multirow[b]{3}{*}{$\begin{array}{l}\text { Inoc } \\
\text { Conc }\end{array}$} \\
\hline & \multicolumn{3}{|c|}{ California } & \multicolumn{3}{|c|}{ Mexico } & \multicolumn{2}{|c|}{ Both } & \\
\hline & Pac-1 & UC-41 & $\begin{array}{c}\bar{x} \\
\left(I^{*} \mathbf{T}\right)^{\mathbf{x}}\end{array}$ & Pac-1 & UC-41 & $\begin{array}{c}\bar{x} \\
\left(I^{*} \mathbf{T}\right)\end{array}$ & $\begin{array}{l}\text { Pac-1 } \\
\left(----T^{*}\right.\end{array}$ & $\begin{array}{r}\text { UC-41 } \\
\text { C-----) }\end{array}$ & \\
\hline $\begin{array}{l}0.0 \\
15.0 \\
60.0 \\
240.0 \\
\text { Reduction }(\%)^{\mathrm{z}}\end{array}$ & $\begin{array}{l}2.05 \mathrm{a}^{\mathrm{y}} \\
1.96 \mathrm{a} \\
1.27 \mathrm{~b} \\
1.24 \mathrm{~b}\end{array}$ & $\begin{array}{l}2.24 \mathrm{a} \\
2.08 \mathrm{a} \\
1.87 \mathrm{a} \\
2.04 \mathrm{a}\end{array}$ & $\begin{array}{l}2.14 \mathrm{a} \\
2.02 \mathrm{ab} \\
1.57 \mathrm{c} \\
1.64 \mathrm{bc} \\
(23.4)\end{array}$ & $\begin{array}{l}2.35 \mathrm{a} \\
2.32 \mathrm{a} \\
1.34 \mathrm{~b} \\
0.62 \mathrm{c}\end{array}$ & $\begin{array}{l}2.77 \mathrm{a} \\
2.07 \mathrm{ab} \\
2.03 \mathrm{ab} \\
1.59 \mathrm{~b}\end{array}$ & $\begin{array}{l}2.56 \mathrm{a} \\
2.20 \mathrm{a} \\
1.69 \mathrm{~b} \\
1.11 \mathrm{c} \\
(56.6)\end{array}$ & $\begin{array}{l}2.20 \mathrm{a} \\
2.16 \mathrm{a} \\
1.31 \mathrm{~b} \\
0.94 \mathrm{c} \\
(57.3)\end{array}$ & $\begin{array}{l}2.50 \mathrm{a} \\
2.07 \mathrm{ab} \\
1.95 \mathrm{~b} \\
1.82 \mathrm{~b} \\
(27.2)\end{array}$ & $\begin{array}{l}2.35 \mathrm{a} \\
2.11 \mathrm{a} \\
1.62 \mathrm{~b} \\
1.38 \mathrm{~b}\end{array}$ \\
\hline
\end{tabular}

${ }^{\mathrm{w}}$ Cultivars were either very susceptible (Pac-1) or moderately susceptible (UC-41) to the foliar phase of safflower rust. Inoc Conc $=$ Inoculation concentration .

${ }^{x}$ Significant interaction occurred between main effects.

${ }^{y}$ Means followed by the same letter in each column are not statistically significantly different $(P=$ 0.05 ), based on the $t$ test option in the general linear models procedure (SAS Institute, Cary, NC). Means are the average of 20 observations.

${ }^{\mathrm{z}}$ Calculated by: [Dry weight (Control) - Dry weight (Dry) / Dry weight (Control)] $\times 100$.

Table 4. Weighted least square means for plant heights of two safflower cultivarsw, Pacific-1 (Pac-1) and UC-41, after inoculation with a 1- $\mu$ l drop containing a known number of teliospores of Puccinia carthami isolates from California or Mexico placed on the hypocotyl near the base of the cotyledons of 2-day-old seedlings

\begin{tabular}{|c|c|c|c|c|c|c|c|c|c|}
\hline \multirow[b]{4}{*}{ Inoc Cone (T) } & \multicolumn{8}{|c|}{ Isolate (I) } & \multirow[b]{4}{*}{$\begin{array}{l}\text { Inoc } \\
\text { Conc }\end{array}$} \\
\hline & \multicolumn{3}{|c|}{ California } & \multicolumn{3}{|c|}{ Mexico } & \multicolumn{2}{|c|}{ Both } & \\
\hline & \multicolumn{8}{|c|}{ Cultivar (C) } & \\
\hline & Pac-1 & UC-41 & $\begin{array}{c}\bar{x} \\
\left(I^{*} \mathbf{T}\right)^{\mathbf{x}}\end{array}$ & Pac-1 & UC-41 & $\begin{array}{c}\bar{X} \\
\left(I^{*} \mathbf{T}\right)\end{array}$ & $\begin{array}{l}\text { Pac-1 } \\
\text { (-----T* }\end{array}$ & $\begin{array}{l}\text { UC-41 } \\
\text { C-----.) }\end{array}$ & \\
\hline 0.0 & $37.5 \mathrm{a}^{\mathrm{y}}$ & $45.6 \mathrm{a}$ & $41.6 \mathrm{a}$ & $36.4 \mathrm{a}$ & $47.1 \mathrm{a}$ & 41.8 & 37.0 & 46.4 & $41.7 \mathrm{a}$ \\
\hline 15.0 & $32.5 \mathrm{ab}$ & $46.2 \mathrm{a}$ & 39.4 & $35.6 \mathrm{a}$ & $41.0 \mathrm{a}$ & 38.3 & 34.0 & 43.6 & $39.4 \mathrm{a}$ \\
\hline 60.0 & $27.2 \mathrm{a}$ & $44.0 \mathrm{a}$ & 35.6 & $23.2 \mathrm{a}$ & $44.3 \mathrm{a}$ & 33.8 & 25.2 & 44.2 & $34.7 \mathrm{~b}$ \\
\hline 240.0 & $30.2 \mathrm{ab}$ & $45.4 \mathrm{a}$ & 37.8 & $14.8 \mathrm{c}$ & $41.2 \mathrm{a}$ & 28.0 & 22.5 & 43.3 & $33.0 \mathrm{~b}$ \\
\hline Reduction $(\%)^{\mathrm{z}}$ & & & $(9.1)$ & & & $(33.0)$ & $(39.2)$ & (6.7) & \\
\hline
\end{tabular}

${ }^{\mathrm{w}}$ Cultivars were either very susceptible (Pac-1, Pacific-1) or moderately susceptible (UC-41) to the foliar phase of safflower rust. Inoc Conc = Inoculation concentration.

${ }^{x}$ Significant interaction occurred between main effects.

${ }^{y}$ Means followed by the same letter in each column are not statistically significantly different $(P=$ 0.05 ), based on the $t$ test option in the general linear models procedure (SAS Institute, Cary, NC). Means are the average of 20 observations.

${ }^{z}$ Calculated by: [Dry weight (Control) - Dry weight (Dry) / Dry weight (Control)] $\times 100$. 


\section{DISCUSSION}

A procedure for the quantitative inoculation of safflower seedlings with teliospores was selected that involves inoculation of 2-day-old safflower seedlings each with a known number of teliospores in a 1$\mu \mathrm{l}$ drop of WAWA on the hypocotyl at the base of the cotyledonary leaves. Seedlings should be planted under sand, given a cool (12 to $15^{\circ} \mathrm{C}$ ) environment (12) with limited watering for 3 weeks after inoculation, and then a warmer $\left(21\right.$ to $\left.25^{\circ} \mathrm{C}\right)$ environment for 2 to 3 weeks. Based on yield component data, watering regime was not a factor after emergence, so normal watering of plants is recommended after they emerge.

Disease incidence was both lower and inconsistent when inoculated seeds were planted under soil (data not shown) or when noninoculated seedlings grew through teliospore-infested sand. HalfonMeiri (6) has shown that the use of teliospore-infested soil resulted in less disease than when contaminated seeds were used. The lower amounts of disease may be due to limited exposure to inoculum (lower concentration and physical separation), soil moisture, or aeration. The procedure described in this paper minimizes these factors as detriments by the use of direct inoculation of seedlings where the plant is most vulnerable, overlaying inoculated seed with sand, and controlling watering until the seedlings have emerged. The use of sand and restricting water before seedling emergence allows for good aeration of the teliospores under moist conditions. Klisiewicz (9) has shown the detrimental effects of too much moisture and the importance of aeration on germination of $P$. carthami teliospores.

Development of this procedure is pivotal to completing the risk assessment of $P$. jaceae for biological control of YST. Sideby-side comparative greenhouse studies are very useful to facilitate judgments about risk under expected field conditions $(3,4)$. In earlier comparisons in the greenhouse, it

Table 5. Mean disease ratings ${ }^{\mathrm{u}}$ and the mean Wilcoxon sums ${ }^{\mathrm{v}}$ for disease 6 weeks after inoculating the primary roots of 2-day-old safflower seedlings with Puccinia carthami teliospores ${ }^{\mathrm{w}}$

\begin{tabular}{|c|c|c|c|c|c|c|c|c|c|}
\hline \multirow[b]{2}{*}{ Isolate $^{y}$} & \multirow[b]{2}{*}{ Cultivar $^{\mathrm{z}}$} & \multicolumn{3}{|c|}{ Watered $^{\mathrm{x}}$} & \multicolumn{3}{|c|}{ Watered $^{\mathrm{x}}$} & \multicolumn{2}{|c|}{$\begin{array}{c}\text { Kruskal-Wallace } \\
\text { test }^{\mathbf{v}}\end{array}$} \\
\hline & & $n$ & Rating & Wilcoxon & $n$ & Rating & Wilcoxon & Chi-sq & $P>$ Chi-sq \\
\hline CAL & Pac-1 & 19 & 2.00 & 14.2 & 20 & 4.00 & 25.5 & 15.46 & 0.001 \\
\hline CAL & UC-41 & 19 & 1.68 & 16.2 & 20 & 3.20 & 23.6 & 5.76 & 0.016 \\
\hline MEX & Pac-1 & 19 & 3.37 & 18.1 & 18 & 4.00 & 20.0 & .098 & 0.323 \\
\hline MEX & UC-41 & 20 & 2.60 & 19.0 & 20 & 3.20 & 22.0 & 1.10 & 0.294 \\
\hline
\end{tabular}

u Disease ratings are from $0=$ no macroscopic symptoms to $4=$ large pustules, elongated, and twisted hypocotyls or plant death.

${ }^{v}$ Calculated for nonparametric data (NPAR1WAY, SAS Institute, Cary, NC).

${ }^{w}$ Data are combined from the 15 and 62.5 teliospores per seedling treatments only; differences were not significant in the controls or in the 240 teliospores per seedling treatments.

x Plants either were watered on a regular basis (Watered) or were allowed to sustain a reversible wilt before watering (Wilted).

${ }^{\mathrm{y}}$ Isolates are designated by location of source. $\mathrm{CAL}=\mathrm{a}$ Californian field isolate. MEX $=$ a Mexican field isolate.

${ }^{\mathrm{z}}$ Cultivars were either very susceptible (Pac-1, Pacific-1) or moderately susceptible (UC-41) to the foliar phase of safflower rust.
The procedure developed for this study is similar to one described by Toussoun et al. (14) to inoculate bean stems with Fusarium solani. A capillary pipette was used to place drops of macroconidia on detached bean stems that were then incubated in a moist chamber and evaluated after 4 days of inoculation. Their procedure was semiquantitative and the placement of inoculum in their study was less critical. In the present study, successful inoculation of safflower seedlings depended on both the amount and the placement of inoculum. Additionally, the teliospore inoculation procedure differs from the capillary pipette procedure by the use of $0.1 \%$ water agar both to keep spores in suspension during quantification and to hold spores in place on the seedling, use of a wetting agent to facilitate suspension of inoculum, and application of a smaller volume of inoculum (1- $\mu \mathrm{l}$ versus $5-\mu \mathrm{l}$ drops) delivered to the plant.

All three safflower cultivars were damaged by infection from $P$. carthami in this study, but differences in cultivar susceptibility were noted. This is based on the statistically significant interactions between cultivar and treatments (Tables 1, 3, and 4) where Pac-1 had greater losses in terms of dry weight and height than the other two cultivars. These results support findings from other studies $(12,16,18,20)$. Evidence from this study also supports data suggesting a correlation between susceptibility of safflower seedlings (from teliospore infestations) and older plants (from urediniospores) $(12,20)$. In the present study, both UC-41 and C/W-74 were less susceptible than Pac-1 to infection by P. carthami. The same order of susceptibility was reported for these cultivars in an earlier study on foliar infections by $P$. carthami (1). In the earlier cultivar study with urediniospores, cultivars least susceptible to $P$. carthami also were least susceptible to $P$. jaceae (1). The hypothesis concerning relative cultivar susceptibility to $P$. carthami and $P$. jaceae now can be tested in studies with teliospores.

Results from the inoculum concentration experiment suggest there is no interaction between yield components (plant height, fresh and dry weights) and water stress after inoculation. This supports findings from an earlier study (12). Although yield components were not affected by watering regime, there was evidence that disease, based on ratings or estimates of plant area infected, was greater when plants were allowed to wilt before watering. Differences noted for watering regime occurred only where disease pressure was lowest, i.e., after inoculation by the CAL isolate at the two lowest teliospore concentrations (15 and 62.5 per seedling). The CAL isolate was less aggressive than the MEX isolate in this study.

Effects of watering on the amount of disease (versus yield) resulting from $P$. 
carthami teliospore inoculations were not reported in earlier studies on safflower rust, suggesting that the inoculation procedure proposed in the present study brings a much greater level of control and sensitivity to investigations of this disease. Otherwise, the proposed procedure compares favorably with other inoculation procedures $(9,12,16-19)$. For these reasons, the procedure developed from this study will be a valuable part in completing the risk assessment of $P$. jaceae for biological control of YST.

\section{ACKNOWLEDGMENTS}

The technical assistance of Dave Koogle is acknowledged, advice on statistics was provided by $\mathrm{J}$. G. Phillips (USDA-ARS-NAA, Philadelphia, PA), the CAL rust isolate and safflower seeds of Pac-1 and UC-41 were provided by John Klisiewicz (USDA-ARS, retired; Davis, CA), the Silwet L-77 was provided by R. C. Ostrowski (United Agri Products, Greeley, CO), the rust isolate MEX was collected by G. L. Peterson (USDA-ARS, Frederick, $\mathrm{MD}), \mathrm{C} / \mathrm{W}-74$ seeds were provided by $\mathrm{Cal} / \mathrm{West}$ Seeds (Woodland, CA), and yellow starthistle seeds were provided by Kathlene Casanave and David Supkoff (CDF\&A, Sacramento, CA). Constructive comments from V. D. Damsteegt, P. W. Tooley, N. W. Schaad (all USDA-ARS, Frederick, MD), A. B. A. M. Baudoin (VPI, Blacksburg, VA), and D. M. Woods (CDF\&A, Sacramento, CA) are gratefully acknowledged.

\section{LITERATURE CITED}

1. Bruckart, W. L. 1989. Host range determination of Puccinia jaceae from yellow starthis- tle. Plant Dis. 73:155-160.

2. Bruckart, W. L., Eskandari, F., and Koogle, D. L. 1997. A procedure to prime teliospores of Puccinia jaceae for germination. Phytopathology 87:S12.

3. Bruckart, W. L. , and Shishkoff, N. 1993. Foreign plant pathogens for environmentally safe biological control. Pages 224-230 in: Pest Management: Biologically Based Technologies. R. D. Lumsden and J. L. Vaughan, eds. American Chemical Society, Washington, DC.

4. Bruckart, W. L., Supkoff, D. M., and Yang, S. M. 1996. Indigenous plant pathogens in evaluations of foreign biological control candidates in the United States of America. Pages 19-26 in: Proc. Int. Symp. Biol. Contr. Weeds, 9th. V. C. Moran and J. H. Hoffmann, eds. University of Cape Town, Cape Town, South Africa.

5. Dhingra, O. D., and Sinclair, J. B. 1985. Basic Plant Pathology Methods. CRC Press, Boca Raton, FL.

6. Halfon-Meiri, A. 1983. Seed transmission of safflower rust (Puccinia carthami) in Israel. Seed Sci. Technol. 11:835-851.

7. Hornby, D., and Ullstrup, A. J. 1965. Physical problems of sampling soil suspensions in the dilution-plate technique. (Abstr.) Phytopathology 55:1062.

8. Klisiewicz, J. M. 1973. Effect of volatile substances from safflower on germination of teliospores of Puccinia carthami. Phytopathology $63: 795$.

9. Klisiewicz, J. M. 1977. Effect of flooding and temperature on incidence and severity of safflower seedling rust and viability of Puccinia carthami teliospores. Phytopathology 67:787790.

10. Melching, J. S., Bromfield, K. R., and King- solver, C. H. 1983. The plant pathogen containment facility at Frederick, Maryland. Plant Dis. 67:717-722.

11. Mortensen, K., Harris, P., and Kim, W. K 1991. Host ranges of Puccinia jaceae, $P$. centaureae, $P$. acroptili, and $P$. carthami, and the potential value of $P$. jaceae as a biological control agent for diffuse knapweed (Centaurea diffusa) in North America. Can. J. Plant Pathol. 13:71-80.

12. Schuster, M. L. 1956. Investigations on the foot and root phase of safflower rust. Phytopathology 46:591-595.

13. Schuster, M. L., and Christiansen, D. W. 1952. A foot and root disease of safflower caused by Puccinia carthami Cda. Phytopathology 42:211-212.

14. Toussoun, T. A., Nash, S. M., and Snyder, W. C. 1960. The effect of nitrogen sources and glucose on the pathogenesis of Fusarium solani f. phaseoli. Phytopathology 50:137-140.

15. Tuite, J. 1969. Plant Pathological Methods. Burgess, Minneapolis, MN

16. Zimmer, D. E. 1962 . Hypocotyl reaction to rust infection as a measure of resistance of safflower. Phytopathology 52:1177-1180.

17. Zimmer, D. E. 1965. Rust infection and histological response of susceptible and resistant safflower. Phytopathology 55:296-301.

18. Zimmer, D. E., and Jensen, J. J. 1970. Seedling rust and yield of safflower. Plant Dis. Rep. 54:364-367.

19. Zimmer, D. E., and Urie, A. L. 1967. Significance of seedling rust resistance of safflower and its relationship to foliage rust resistance. Phytopathology 57:772-776.

20. Zimmer, D. E., and Urie, A. L. 1968. Influence of foliage rust on yield, test weight, and oil percentage of safflower seed. Plant Dis. Rep. 52:876-878. 